\title{
Grande imprensa: valores e/ou características veiculadas por jornais brasileiros para descrever a participação da seleção brasileira de futebol na Copa do Mundo de 1998 em França ${ }^{1}$
}

\author{
HATJE, Marli; CARVALHO, Sérgio ${ }^{3}$
}

\section{Resumo}

A presente pesquisa teve por objetivo analisar os valores e/ou características veiculados através do conteúdo utilizado por jornais brasileiros para descrever a participação da seleção brasileira de futebol e seus adversários na semifinal e na final na Copa do Mundo de 1998 em França. A análise de conteúdo foi aplicada à cobertura realizada pelos jornais Folha de São Paulo (SP), O Globo (RJ) e Zero Hora (POA), nos dias 6, 7, 8, 11, 12 e 13 de julho de 1998, período em que foram disputadas a semifinal (Brasil x Holanda) e a final (Brasil x França). Definiu-se sete categorias, divididas em subcategorias. No total foram consideradas 962 unidades de análise (títulos, linhas de apoio, olho e fotografias/legendas), do gênero informativo. A discussão dos dados centrou-se nas análises quantitativa e qualitativa e na análise comparativa entre os veículos. A imprensa brasileira analisada veicula e exalta valores e características inerentes ao futebol e ao próprio povo brasileiro em época de Copa do Mundo. Exalta atletas em detrimento do grupo, explora, promove e estimula os espetáculos esportivos através do uso de linguagem/imagem emotiva e de expressões bélicas e militares para estimular a rivalidade. De modo geral caracterizou-se mais como informativa, do que educativa e/ou formativa.

Palavras-Chaves: jornalismo esportivo; Comunicação e esporte; educação física e mídia.

\section{Introdução}

No Brasil existem inúmeros trabalhos sobre o futebol enquanto fenômeno social, especialmente no campo da sociologia. No entanto, estudos que privilegiam a relação entre essa mo-

\footnotetext{
${ }^{1}$ Artigo elaborado a partir da tese de doutoramento, defendida em 15 de agosto de 2000, junto ao Programa de Pós-Graduação em Ciência do Movimento Humano, Subárea Comunicação, Movimento e Mídia na Educação Física, do Centro de Educação Física e Desportos (CEFD) da Universidade Federal de Santa Maria (UFSM)- RS.

${ }^{2}$ Prof ${ }^{a}$ Adj. Dr ${ }^{a}$ do Centro de Educação Física e Desportos da UFSM

${ }^{3}$ Prof. Tit. Dr. do Centro de Educação Física e Desportos da UFSM.
}

Revista Kinesis, Santa Maria, $N^{\circ}$ Especial, p. 64-154, nov. 2001 
dalidade, o esporte de forma geral e a imprensa são praticamente inexistentes em qualquer área acadêmica. Atualmente, ainda não existe uma teoria ou um modelo de suporte - interdisciplinar ${ }^{4}$ - para o estudo da linguagem esportiva no Brasil, embora alguns pesquisadores estejam dando os primeiros passos nesse sentido, como José Maurício Capinussú, por exemplo. Entende-se, no entanto, que a partir de trabalhos realizados no Instituto Nacional de Educação Física de Catalúnia (INEFC), Lleida/Espanha e na Subárea Comunicação, Movimento e Mídia na Educação Física do Programa de Pós-Graduação em Ciência do Movimento Humano (CEFD/UFSM) ${ }^{5}$, podemos implementar, de fato, uma tentativa de trazer novos elementos à discussão do futebol, do esporte e da própria imprensa, bem como para as relações que se estabelecem entre eles, a partir do conteúdo de sua linguagem.

Várias questões, que a alguns anos nos inquietam, motivaram-nos para realizar a pesquisa, ou seja, como a imprensa esportiva brasileira influencia a sociedade? Ela é capaz de mudar comportamentos e atitudes ao veicular valores e/ou características sociais? Quais os valores e/ ou características que ela reforça quando está em evidência um evento como a Copa do Mundo e como ela explicita eles através da linguagem? Será que a imprensa brasileira estimula a violência com a linguagem que usa para descrever eventos esportivos? Qual a relação entre o aspecto econômico do futebol e a imprensa? Por que a imprensa brasileira exalta tanto jogadores individualmente quando eles integram uma equipe? Além da possibilidade de criar o herói ou o personagem que outra leitura podemos fazer?

Antes de contextualizar o trabalho, cabe destacar que futebol e esporte se confundem na imprensa brasileira. Esporte e futebol são considerados sinônimos. Por isso, fica praticamente impossível definí-los - principalmente se discutindo as relações históricas entre imprensa e esporte (todas as modalidades) e futebol. Os estudos revisados não estabelecem essa diferença e quando ela existe, ora tratam do esporte, ora do futebol como sinônimos. Ao adentrar-se-á a pesquisa propriamente dita, utilizar-se-á a expressão futebol ou modalidade esportiva, pois o estudo está centrado no futebol e não no esporte de maneira geral.

As relações entre esporte e imprensa não são recentes, embora sejam raros os registros que documentem essas relações. Para Constantino (1992) as relações entre a comunicação social e o esporte, sobretudo através da imprensa escrita, são visíveis a partir de finais do século XIX, embora, segundo Erbolato (1985) boa parte dos noticiários limitava-se a anunciar as disputas e a dar os resultados em poucas linhas. "Até o início da década de 40 , o cronista esportivo ocupava a posição mais baixa na hierarquia dos jornais, e o futebol mantinha discreto destaque na imprensa escrita" Marques (apud Carvalho \& Hatje, 1998).

O esporte brasileiro desenvolveu-se, em grande parte, aliEerçado na divulgação pelos meios de comunicação. Primeiro apoiou-se no jornalismo impresso e depois no radiofônico e televisivo. A comunicação social, através de seus meios, é parte integrante do espetáculo esportivo, assim como este é parte integrante dos meios de comunicação. Espetáculo esportivo é entendido aqui como o resultado da associação entre a comunicação social e o esporte que

\footnotetext{
${ }^{4}$ Este trabalho foi elaborado sob a premissa de que a interdisciplinaridade acontece quando diferentes áreas do conhecimento se unem em torno de um objeto de estudo comum, não negando assim as especificidades, mas respeitando o território de cada campo de conhecimento. Deve-se trabalhar o conhecimento através da interdependência e de conexões recíprocas (HATJE, 2000).

${ }^{5}$ A Subárea foi implantada no Programa de Pós-Graduação em Ciência do Movimento Humano, do Centro de Educação Física e Desportos da UFSM/RS, em 1991 pelo professor Dr. Sérgio Carvalho. Em 1994, foi reconhecida como grupo emergente pelo então presidente da Sociedade Brasileira de Estudos Interdisciplinares da Comunicação (INTERCOM), Adolpho Carlos Françoso Queiroz, em artigo publicado na revista Comunicação Rural. Em 1996, o Laboratório propôs a criação do GT Mídia e Esporte na INTERCOM, implantado neste mesmo ano, durante o Congresso da entidade em Londrina - PR.7
} 
fascina e seduz multidões. Essa associação com a comunicação trouxe conotações de espetáculo, direcionado para entreter o público (Camargo, 1998).

Buscando sustentação em Cazorla Prieto, Tubino (1992), entende que os espetáculos esportivos manifestam a própria importância do esporte, tornando-se verdadeiros retratos da sociedade de massas, ao mesmo tempo que servem também de escapismos do homem moderno. Já para Prieto (apud Tubino, 1987), o "espetáculo esportivo exerce uma grande atração sobre a massa de cidadãos, suplantando de forma nítida a maioria dos outros tipos de espetáculos, inclusive, levando os espectadores a processos de identificação com os ídolos dos estádios, conduzindo-os a emoções fortíssimas de sofrimento, stress, alegria, prazer, convivência, etc".

Embora freqüentemente se discuta o futuro do jornal diário, esse trabalho será elaborado na premissa de que é um veículo que se fortalece a cada dia, mesmo com o avanço dos meios eletrônicos e que ele ainda tem a função de aprofundar as informações veiculadas, diferenciando-se assim dos veículos rádio e televisão.

O futebol tem significado social para o brasileiro. O futebol faz parte de sua cultura ${ }^{6} \mathrm{e}$ junto com o Carnaval expressa parte dela, constituindo-se ambos nos aspectos que mais identificam o brasileiro, especialmente no exterior.

$\mathrm{O}$ esporte proporciona a experiência do êxito e da vitória, do fracasso e da derrota. O futebol é representante legítimo dessa afirmação. É nele e através dele que acontecem todos os tipos de emoções. "As competições proporcionam emoção e drama, porque o resultado é incerto. A emoção e o drama acarretam a participação ativa dos espectadores, que gritam, aplaudem e identificam-se, pois já praticaram ou conhecem as regras do jogo. Amam e odeiam na mesma proporção" (Lever, 1983).

Para Damatta (1994), no Brasil, indiscutivelmente, é através do futebol, que o povo pode juntar os símbolos do Estado nacional (a bandeira, o hino, as cores nacionais). O esporte libera as emoções mais contidas do cidadão. O esporte "também oferece uma oportunidade para a demonstração de nosso patriotismo" (Camargo, 1998). O futebol faz o brasileiro mais patriota, o faz amar o País, especialmente em época de Copa do Mundo. O Brasil tem tradição no futebol e, sobretudo, no evento. É o único tetracampeão. É através dele que o brasileiro se identifica e se sente identificado. A identificação é um mecanismo de atuação inconsciente que se instala entre o que seduz e o seduzido. Nesse sentido, o indivíduo se reconhece ou, ainda, se projeta.

Segundo Pallares (1997) toda competição esportiva, devido a sua lógica antagônica, produz processos de identidade. Esse fenômeno acontece de forma inten̉sa no futebol. O mecanismo psicológico faz com que uma multidão de pessoas, por exemplơ še sente representada pelos jogadores e ao mesmo tempo se sente também protagonista do evento, chegando muitas vezes a níveis de implicação extremas.

Diante da importância dada ao futebol, quais as atitudes que ele sucita e que são veiculadas pela imprensa? Se o futebol é paixão, é emoção, é violência; se o futebol é história e cultura, como a imprensa se vale desses conteúdos em sua linguagem, quando realiza cobertura jornalística envolvendo a modalidade? Essas manifestações ficam claro nas informações veiculadas? Con-

\footnotetext{
${ }^{6}$ Para compreender melhor as discussões e os conceitos que envolvem a cultura brasileira, buscamos referências em Ortiz (1988), Santos (1994) e Bosi (1999). Este trabalho, como aborda o brasileiro e, aspectos de sua cultura, achamos oportuno conceituar cultura. O conceito que sustenta, em parte. o trabalho refere-se as concepções de Santos (1994). Cultura para ele são todos os aspectos de uma realidade social, ou seja, é tudo aquilo que caracteriza a existência social de um povo, de uma nação ou de grupos de uma sociedade. Cultura é também conhecimento. São as idéias e as crenças de um povo.
}

Revista Kinesis, Santa Maria, $N^{\circ}$ Especial, p. 66-154, nov. 2001 
siderando esses aspectos, ela reforça os valores ou as características inerentes ao futebol? Ela muda comportamentos?, intensifica os sentimentos?

Assumimos a hipótese que a linguagem da imprensa esportiva impressa brasileira está imbuída dos elementos manifestos e expressos através do futebol e que também identificam o povo brasileiro e a própria imprensa. "O futebol é rico em imagens e mensagens representativas da comunidade". A afirmação de Helal (1997) ratifica a asserção, ainda mais quando destaca que "a imprensa é um importante registro das crenças, valores, contradições, dramas e imagens das sociedades modernas".

Diante disso e a partir de estudos já realizados em nível de mestrado e como docente/pesquisadora em instituição de ensino superior, procuramos aprofundar as questões como, onde, quando e porque a imprensa trabalha esses valores e/ou características numa parcela da sociedade (leitores de jornais). Depois a partir de inferências pretendo destacar os (possíveis) efeitos desse fato. Entende-se por valor neste trabalho os símbolos como a bandeira, as cores do Brasil, o hino nacional, e como características, aspectos que caracterizam as pessoas, como valentia, coragem, esforço e esperança.

O futebol integra o chamado esporte moderno, esporte que pode ser classificado sob vários aspectos (esporte participação; esporte educação e esporte rendimento, Tubino (1992). Neste estudo, nos interessa, no entanto, abordar o futebol enquanto competição de alto nível, de rendimento, esporte performance, aquele que segundo Tubino (1992), exige uma organização complexa e altos investimentos e que é exercido sob regras preestabelecidas pelos organismos internacionais de cada modalidade. Interessa-nos, portanto, estudá-lo enquanto prática dos chamados talentos esportivos.

Para analisar os valores e/ou as características veiculadas, através do conteúdo utilizado por jornais brasileiros para descrever a participação da seleção brasileira de futebol e seus adversários na semifinal e final na Copa do Mundo de 1998 em França, definiu-se a amostra a partir dos jornais: Folha de São Paulo (SP), O Globo (RJ) e Zero Hora (POA) e o corpus composto dos títulos, das linhas de apoio, dos olhos e das fotografias/legendas das matérias que se referem à cobertura da seleção brasileira e seus adversários nos jogos da semifinal e da final da competição. A análise do conteúdo - em seus aspectos quantitativo e qualitativo - foi o método utilizado ao estudo e observou, basicamente, as orientações de Bardin (1977) e Pallarés (1997)7.

Mesmo que os resultados possam servir de subsídios para aperfeiçoar a linguagem utilizada para descrever fenômenos ou eventos esportivos nos meios impressos e eletrônicos, este não é o objeto buscado. Tampouco definir critérios para o aperfeiçoamento da cobertura já existente. A metodologia utilizada, crê-se, poderá sustentar noyos estudos, sobretudo os interdisciplinares, importantes para propor possíveis formas de interferir na qualidade do jornalismo esportivo brasileiro.

\section{A pesquisa}

A pesquisa, de caráter interdisciplinar, é um estudo no âmbito da Educação Física/Esporte e da Comunicação Social, através de seus meios. Envolve o fenômeno futebol e o conteúdo da

\footnotetext{
${ }^{7}$ Cinco, das sete categorias definidas para esta pesquisa, foram extraídas do estudo Identidad émica, nacionalismo, emociones y violência en el fútbol, elaborado pelo autor, em 1997 na Espanha. Além dos aperfeiçoamentos necessários às categorias por ele utilizadas para ajustá-las à realidade brasileira, criou-se outras duas, com as respectivas subcategorias, para contemplar a proposta do trabalho.
} 
linguagem no jornalismo esportivo impresso e associa estudiosos das áreas da Educação Física/ Esporte, Comunicação Social, Sociologia, Psicologia e Antropologia, principalmente. O futebol foi estudado enquanto competição de alto nível, por isso a referência a pesquisadores dessas áreas se faz necessária. Muitos deles atuam na modalidade, seja como professores de escolinhas, como integrantes de equipes multiprofissionais no treinamento e condicionamento de atletas, ou como pesquisadores e estudiosos do futebol enquanto fenômeno social, representando parte da cultura brasileira.

A amostra foi definida a partir dos jornais Folha de São Paulo (SP), O Globo (RJ) e Zero Hora (POA) e o corpus composto dos títulos, das linhas de apoio, dos olhos e das fotografias/ legendas das matérias que se referem à cobertura da seleção brasileira e seus adversários nos jogos da semifial e final da Copa do Mundo de 1998 em França.

Elegeu-se a análise de conteúdo como a método para a realização do trabalho, com uma abordagem quantitativa/qualitativa. A primeira porque permite o índice de frequiência e a segunda porque possibilita inferências a partir das ocorrências. Para a análise e as inferências utilizou-se, entre outros, Daolio (1997), Helal (1990), Santos (1998), Lever (1983), Alcoba (1980, 1987, 1999), Berger (s/d), Capinussú (1988 e 1997), Dunning (1990, 1992), Gonzalez \& Saavedra (1996), Tubino (1987 e 1992), Rodrigues (1994), Amaral (1978), Beltrão (1969), Marques de Melo (1972, 1985 e 1994 ) e Carvalho e Hatje (1998), Erbolato (1981 e 1985).

A análise de conteúdo foi realizada a partir de categorias pré-estabelecidas. A categorização, um processo estruturalista comporta duas etapas: a) o isolamento dos elementos de análise e b) a classificação, procurando uma certa organização às mensagens, tem por objetivo fornecer, por condensação, uma representação simplificada dos dados brutos. Para a definição das categorias utilizou-se, além de Bardin (1997) e Pallarés (1997), estudos realizados por Gonzáles \& Saavedra (1996), Hatje, Carvalho \& Palma (1998/1999).

\section{Metodologia}

\section{Procedimentos metodológicos}

\section{Técnica de coleta dos dados}

Os jornais selecionados. a amostragem e a seleção das matérias

A unidade de contexto que compôs a amostra foi do gênero informativo e da editoria de esporte, referente a participação da seleção brasileira na Copa do Mundo de 1998 em França, veiculadas nos jornais Folha de São Paulo (São Paulo), O Globo (Rio de Janeiro) e Zero Hora (Porto Alegre). Foram consideradas as matérias publicadas pelos três veículos nos dias 6, 7, 8, 11,12 e 13 de julho, período que compreendeu a disputa da semifinal ( 7 de julho) e da final (12 de julho) da competição.

Do material produzido considerou-se apenas aquele publicado e veiculado nas duas partidas durante três dias: o dia anterior, o dia e o dia posterior ao jogo em todos os veículos (edição normal ou caderno especial), inclusive as capas e as contracapas dos jornais.

Revista Kinesis, Santa Maria, $N^{\circ}$ Especial, p. 68-154, nov. 2001 
A seleção dos jornais à pesquisa justifica-se, principalmente, pela sua circulação e tiragem no Brasil e pela sua importância no cenário do jornalismo brasileiro.

Foram selecionadas as três principais matérias de cada página dos jornais e dos Cadernos de esportes nos dias citados. Entendeu-se por principais matérias:

1) A matéria que abre a página com ou sem foto;

2) Matérias com linhas de apoio, olho e fotos;

3) Matérias mais longas

4) não serão consideradas:

a) colunas assinadas;

b) entrevistas realizadas com jogadores, membros da comissão técnica ou torcedores;

c) páginas em que são feitas avaliações de grupos de atletas, ou seja, quando aparecem os bone $\cos ^{8}$ dos jogadores com uma legenda.

d) páginas com publicação de fotografias/legendas foram consideradas todas aquelas vinculadas as duas partidas envolvendo a seleção brasileira e seus adversários;

5) na capa foram considerados os títulos, as linhas de apoio, fotos, e os olhos referentes aos jogos dois jogos, exceto quando se referiam a colunas ou às entrevistas com jogadores, membros da comissão técnica ou torcedores;

6) nas páginas unificadas foi considerada a matéria principal - que caracteriza a unificação - e as duas mais importantes de cada página.

\section{$\underline{\text { Seleção das unidades de registro }}$}

Consiste na identificação dos títulos, das linhas de apoio, dos olhos e das fotografias/ legendas nos três jornais a serem utilizados à pesquisa. No total foram selecionadas 962 unidades, sendo 425 da semifinal e 537 da final.

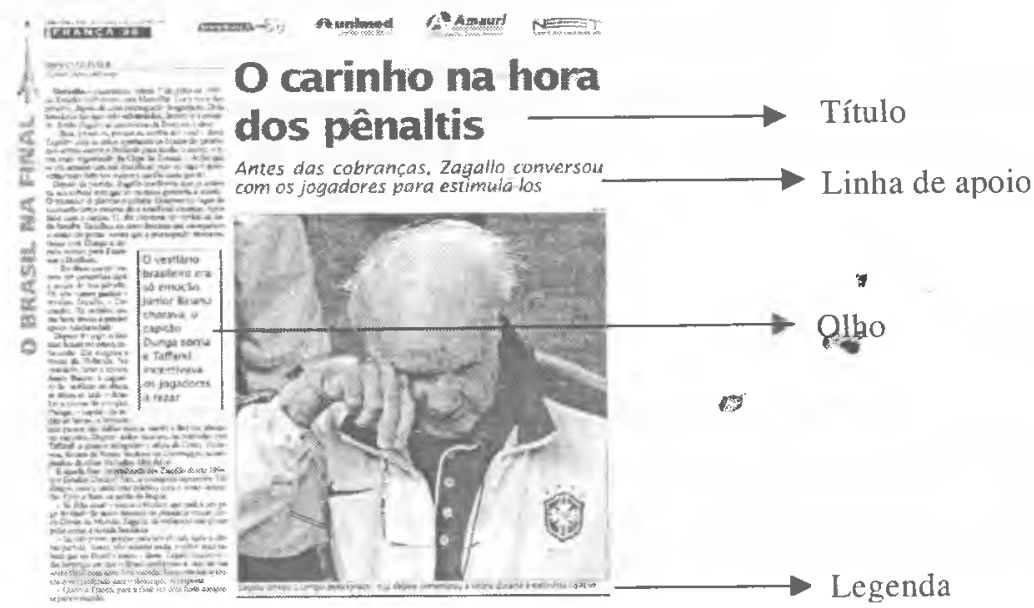

Figura 1 - Página modelo com identificação das unidades de registo utilizadas ao estudo (ZH, 08/ 07/98, p. 6)

${ }^{8}$ Fotografia de pessoa, para ser publicada em jornal. Semelhante a uma foto $3 \times 4$. 


\section{Classificação das unidades de registro nas categorias}

1) Os títulos, as linhas de apoio, os olhos e as fotografias/legendas foram classificados numa das categorias definidas à análise;

2) cada um deles foi classificado separadamente, embora fosse procedente classificar título e linha de apoio na mesma categoria, uma vez que a linha de apoio é considerado complemento do título. O procedimento se justifica porque nem sempre ambos podem ser classificados na mesma categoria;

3) quando a classificação permitiu o enquadramento da unidade de registro em mais de uma categoria adotou-se os seguintes critérios:

3. 1 Prioridade para a atuação da seleção brasileira;

3.2 questão da primazia, ou seja, o mais importante em primeiro lugar. Por exemplo: Começa a batalha entre Brasil e França. França é a favorita. Nesse caso, classificou-se o título na categoria como linguagem bélica e não como exaltação do adversário, como sugere o complemento;

3.3 em relação às fotografias/legendas - As fotografias serão analisadas da seguinte forma: a classificação nas categorias é quanto a imagem, pois acredita-se que a primeira leitura que o leitor faz é a partir da imagem (impacto). Nesse sentido serão explorados os símbolos como a bandeira, as cores brasileiras, etc e a emoção manifesta pelos envolvidos no Mundial. Quando a imagem não permite uma definição/significação clara, a classificação ocorre a partir da legenda. Para a foto-legenda, o critério foi o mesmo.

\section{As categorias e suas subcategorias}

A análise do conteúdo foi realizada a partir de sete categorias, divididas em 81 subcategorias. As categorias foram definidas tomando-se por referência estudos realizados na Universidade de Lleida/Espanha, por Pallarés (1997). No entanto, para adequá-los à realidade brasileira foram utilizadas, principalmente, pesquisas realizadas no Laboratório de Comunicação, Movimento e Mídia na Educação Física do CEFD/UFSM, por Hatje, M. Carvalho, S. \& Palma, L. (1998/1999).

\section{Tracos étnicos}

Expressa, através da imprensa brasileira escrita (jornaîis) os valores brasileiros, holandeses e franceses manifestados pelo orgulho pátrio, pela denotação xenófoba ou pela comparação de uma imagem étnica brasileira, francesa e holandesa em relação a outras peculiaridades culturais e étnicas. É composta de três subcategorias:

1) Caráter xenófobo-racista

2) Exaltação da etnia e do nacionalismo

3) Comparação étnica e nacionalista 


\section{$\underline{\text { Relações nacionais e internacionais }}$}

Realça a "invasão" de comentários, fotografias ou anedotas que tratam de exaltar, de modo insistente, as características e os valores da equipe brasileira e de seus adversários, saindo de suas peculiaridades estritamente futebolísticas e entrando em apelações emotivas e/ou símbolos patrióticos. Também considerou-se os aspectos negativos, tanto através das ridicularizações expressas quanto dos comentários negativos em relação a atuação das equipes do Brasil, da Holanda e da França. É composta de 10 subcategorias:
A) Registros relativos à equipe nacional
1 Exaltação da seleção brasileira
2 Exaltação do patriotismo emocional
3 Ridicularização da seleção
4 Comentários e valores negativos da seleção
5 Tópicos e metáforas dirigidas à seleção brasileira e à nacionalidade

\section{B) Registros relativos às seleções adversárias}

1 Exaltação e reforço do adversário

2 Exaltação do patriotismo emocional do adversário

3 Tópicos e metáforas dirigidas aos adversários e às nacionalidades países

4 Ridicularização dos adversários

5 Comentários e valores negativos dos adversários e das nacionalidades

\section{$\underline{\text { Registros relativos à individualidades na equipe nacional e adversária }}$}

Realça a valorização das individualidades por parte da imprensa brasileira, em detrimento do grupo, ou seja, das seleções das quais fazem parte os atletas exaltados. Oito subcategorias a compõem:

1 Exaltação de jogador da seleção nacional

2 Exaltação de jogador da seleção adversária

3 Exaltação do técnico da equipe nacional

4 Exaltação do técnico da equipe adversária

5 Exaltação de membros da comissão técnica da equipe nacional

6 Exaltação de membros da comissão técnica da equipe adversária

7 Exaltação de dirigentes do futebol nacional

8 Exaltação de dirigente do futebol no país adversário

\section{Traços de violência}

Salienta as condutas, as expressões e as apelações à violência que apareceram nos veículos estudados, associados às seleções brasileira, holandesa e francesa de futebol. Como as notícias e as expressões de violência explícita ou implícita são variadas optou-se em manter as sete 
classes para detectá-los em 49 subcategorias. A diversificação deve ser levada em conta, pois a freqüência de alguns registros é bem superior em relação a outros ${ }^{9}$. As subcategorias que a compõem são:
A) Jogadores
1 Violência entre jogadores
2 Violência entre jogadores e treinador
3 Violência entre jogadores e comissão técnica
4 Violência entre jogadores e meios de comunicação
5 Violência entre jogadores e torcedores
6 Violência entre jogadores e dirigentes esportivos
7 Violência entre jogadores e árbitros
8 Violência entre jogadores e a força da ordem

\section{B) Treinador}

1 Violência entre treinadores

2 Violência entre treinador e jogadores

3 Violência entre treinador e comissão técnica

4 Violência entre treinador e dirigente esportivo

5 Violência entre treinador e árbitro

6 Violência entre treinador e torcedores

7 Violência entre treinador e a força da ordem

8 Violência entre treinador e meios de comunicação

\section{C) Comissão técnica}

1 Violência entre membros da comissão técnica

2 Violência entre comissão técnica e jogadores

3 Violência entre comissão técnica e treinador

4 Violência entre comissão técnica e dirigente esportivo

5 Violência entre comissão técnica e árbitro

6 Violência entre comissão técnica e torcedores

7 Violência entre treinador e a força da ordem

8 Violência entre comissão técnica e meios de comunicação

\section{D) Dirigentes esportivos}

1 Violência entre dirigentes esportivos

2 Violência entre dirigentes esportivos e comissão técnica

3 Violência entre dirigentes esportivos e jogadores

\footnotetext{
${ }^{9} \mathrm{O}$ grande número de subcategorias voltadas ao aspecto violência, deve-se ao fato de elas terem sido definidas na Inglaterra c. posteriormente, adaptados na Espanha. Na Inglaterra, principalmente, existem muitas pesquisas voltadas à violência no futebol, com ênfase ao comportamento dos hooligans, várias coordenadas pelo professor Eric Dunning, da Universidade de Leicester.
}

Revista Kinesis, Santa Maria, $N^{\circ}$ Especial, p. 72-154, nov. 2001 
4 Violência entre dirigentes esportivos e treinador

5 Violência entre dirigentes esportivos e árbitro

6 Violência entre dirigentes esportivos e torcedores

7 Violência entre dirigentes esportivos e a força da ordem

8 Violência entre dirigentes esportivos e meios de comunicação

E) Torcedores

1 Violência entre torcedores

2 Violência entre torcedores e jogadores

3 Violência entre torcedores e treinador

4 Violência entre torcedores e dirigente esportivo

5 Violência entre torcedores e árbitro

6 Violência entre torcedores e a força da ordem

7 Violência entre torcedores e a comissão técnica

8 Violência entre torcedores e meios de comunicação

\section{F) Meios de comunicação}

1 Violência entre MC

2 Violência entre $\mathrm{MC}$ e jogadores

3 Violência entre $\mathrm{MC}$ e treinador

4 Violência entre $\mathrm{MC}$ e dirigente esportivo

5 Violência entre $\mathrm{MC}$ e árbitro-

6 Violência entre $\mathrm{MC}$ e torcedores

7 Violência entre MC e a força da ordem

8 Violência entre MC e comissão técnica

\section{G) Linguagem}

\section{Linguagem bélica}

\section{$\underline{\text { Tracos sexistas }}$}

Identifica vocábulos e apelações machistas, que têm çaracterizado a cultura do futebol. Buscou-se saber se a imprensa reforçou a característica ou se ela intercedeu com outras expressões em consonância com tempos mais modernos. Duas subcategorias a compõem:

1 Apelações de virilidade

2 Ridicularizações sexistas

\section{Tracos emocionais}

Faz alusão às expressões emocionais protagonizadas por jogadores, espectadores, dirigentes, treinadores e a própria imprensa. Identificou-se aquelas manifestações explícitas refe- 
rentes as emoções: tristeza, alegria, raiva, frustração, a tensão, etc. É composta de seis subcategorias:

1 Manifestações emocionais dos treinadores

2 Manifestações emocionais dos jogadores

3 Manifestações emocionais dos torcedores

4 Manifestações emocionais expressas pela imprensa

5 Manifestações emocionais da comissão técnica

6 Manifestações emocionais de dirigentes esportivos

\section{Aspectos adjacentes às partidas}

Identifica as referências que a imprensa fez ao futebol, enquanto política, história e negócio. É composta de três subcategorias:

1 Valorização de aspectos políticos

2 Valorização de aspectos de publicidade e de marketing

3 Valorização da história do futebol

\section{Descrição e análise dos resultados}

O índice geral de ocorrência das categorias na final e semifnal revela que durante a cobertura das partidas entre Brasil x Holanda e Brasil x França, na Copa do Mundo de 1998, os conteúdos mais veiculados pela imprensa foram aqueles pertencentes as seguintes categorias:

$1^{\circ}$ ) Relações nacionais e internacionais, com 252 ocorrências (26,3\%). Nessa categoria destacou-se conteúdos, de formas positiva e/ou negativa, das equipes nacional e adversária. Os veículos fizeram referências às características e/ou valores da seleção brasileira e de seus adversários, saindo de suas peculiaridades estritamente futebolísticas e entrando também em apelações emotivas e/ou símbolos patrióticos. Dessa categoria faz parte o registro correspondente ao sentimento patriótico (a exaltação do patriotismo emocional), que valoriza fundamentalmente as representações simbólicas ligadas ao sentimento nacionalista. Muitos de seus registros funcionaram também como traços emocionais.

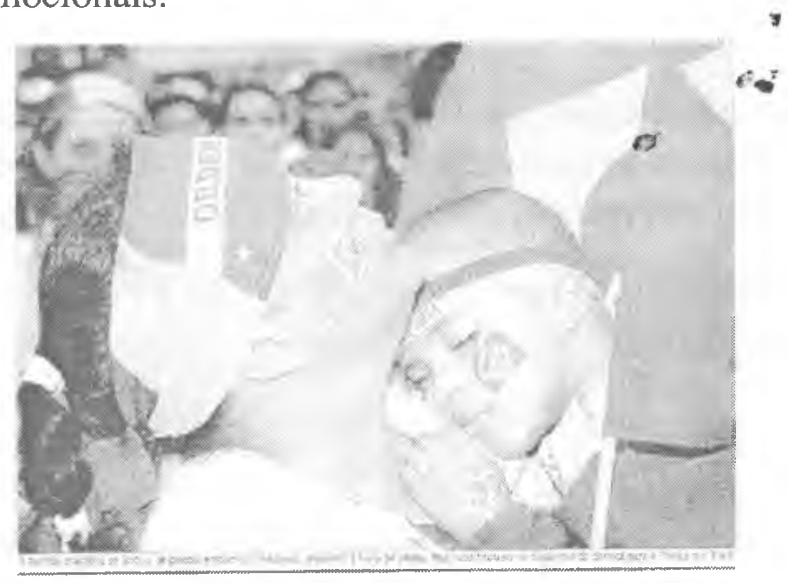

Figura 2 - Exaltação do patriotismo emocional (ZH, 13/07/98)

Revista Kinesis, Santa Maria, $N^{\circ}$ Especial, p. 74-154, nov. 2001 
A partir dos dados é possível afirmar que a imprensa brasileira dedicou.mais espaço à seleção nacional do que às seleções adversárias em sua cobertura, com índices de 14,6\% e $11,5 \%$, respectivamente. No entanto, ela exaltou mais as adversárias $(4,6 \%)$ do que a seleção nacional $(1,9 \%)$, nas duas últimas partidas da Copa; consequentemente reforçou aspectos negativos $(6,2 \%$ considerando-se comentários negativos e ridicularização) em relação a equipe brasileira. Defesa é a pior desde Copa de 38 (FSP-13/07/98) é um exemplo.

\section{FOLHA DE S.PAULO}

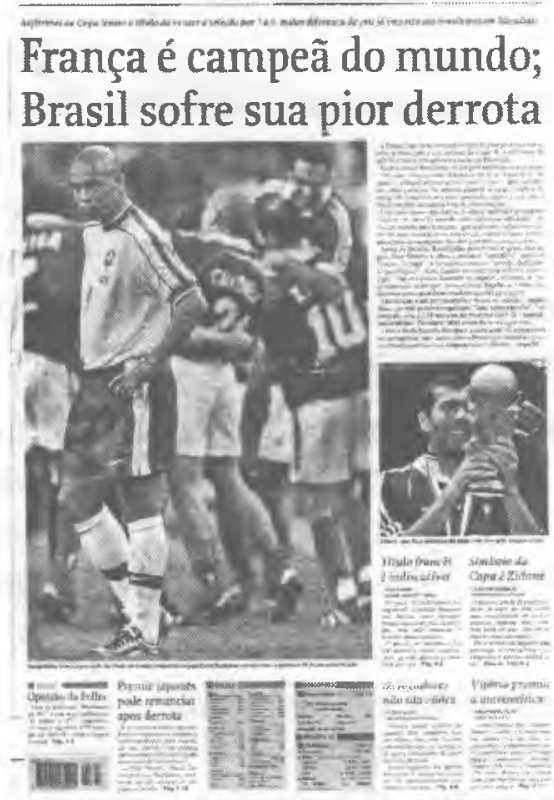

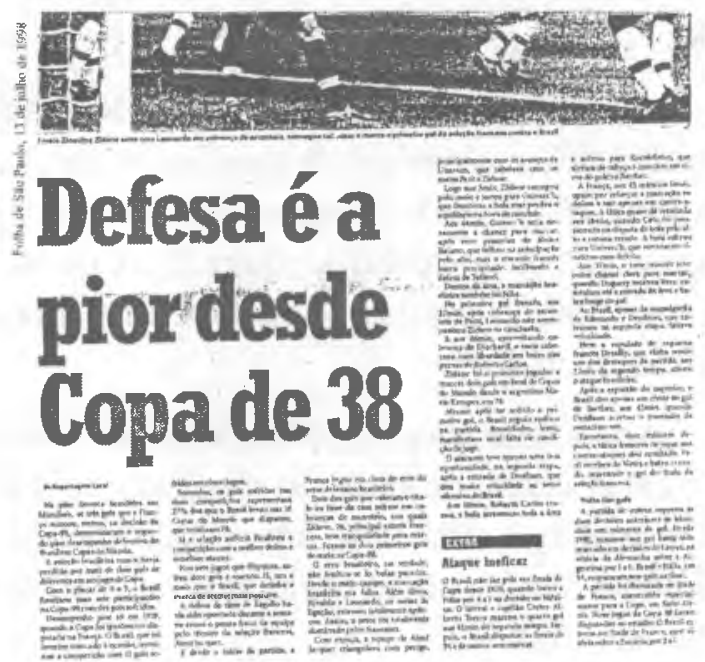

Figura 3 e 4 - Exaltação do adversário e comentário negativo da seleção nacional (FSP, 13/07/ 98 , capa)

Durante todo o período da cobertura analisada, houve alternância entre a exaltação e os comentários e/ou valores negativos. A imprensa brasileira criticou mais a seleção nacional do que as adversárias (5,4\% contra $2,3 \%$, respectivamente). A ocorrência de aspectos positivos ou negativos está diretamente relacionada ao resultado dos jogos e a rivalidade que existe entre as seleções, rivalidade essa exaltada antes das partidas, para promover, de certa forma, o espetáculo

A imprensa ao publicar frases como "a equipe da Holanda é melhor que a do Brasil (07/ 07/98), ela aquece o espetáculo, cria expectativa e a rivalidade entre as torcidas cresce.

$\left.2^{\circ}\right)$ Registros relativos à individualidades nas equipes racional e adversária. com 213 ocorrências $(22,1 \%)$, foi a segunda categoria que mais apareceu. Ao exaltar jogadores, técnicos e/ou membros da comissão técnica das equipes nacional e adversária, os veículos deixam de valorizar a seleção enquanto grupo. É dessa categoria que faz parte a subcategoria Exaltação de jogador da seleção nacional. que mais apareceu nos três jornais considerados à pesquisa, considerando-se a semifinal e final, com 44,7\%. Os jornais que sustentam o índice são Zero Hora, de Porto Alegre, e O Globo, do Rio de Janeiro.

A exaltação de jogadores da seleção nacional $(13,1 \%)$ e das seleções adversárias $(6,4 \%)$ foram as subcategorias mais destacadas pela imprensa brasileira na categoria Registros relativos à individualidades na equipe nacional e adversária. A importância das exaltações aumenta 
na medida em que, boa parte delas, são publicadas e veiculadas nas capas dos jornais e dos cadernos de esportes, espaços considerados nobres na imprensa brasileira.

Ao exaltar atletas, a imprensa reforça o conflito potencial preconizado por Vogel, ou melhor, a imprensa atribui os resultados, ou mesmo a esperança de uma vitória, a determinados jogadores e não à seleção, embora em algumas oportunidades o desempenho de alguns jogadores seja fundamental para a vitória. O goleiro Taffarel é um exemplo disso. A exaltação evidenciou-se nos três veículos: Taffarel pega dois pênaltis e leva o Brasil à final da Copa (FSP - 08/ 07/98); Brasil na final pelas mãos de Taffarel (OG-08/07/98); Gaúcho de mãos santas (ZH-08/ 07/98).

A exaltação dos técnicos das seleções foi evidenciada conquistando, porém, um espaço apenas razoável ( $1,9 \%$, nas partidas da semifinal e final). A relação entre treinadores e meios de comunicação oscila entre altos e baixos durante um evento como o Mundial de Futebol. A relação está diretamente relacionada ao desempenho da equipe. Na Copa do Mundo de 1998, a relação entre Zagallo e a imprensa foi mais cordial do que aquela entre Carlos Alberto Parreira e a imprensa na Copa do Mundo de 1994, nos Estados Unidos ${ }^{10}$.

Ao mesmo tempo que exalta atletas e treinadores, a imprensa critica com veemência outros. Isso, muitas vezes, depende do resultado do jogo e do desempenho deles, principalmente com os quais a imprensa estabelece um relação de simpatia e antipatia. O jornal Zero Hora publicou um exemplo no dia da partida semifinal contra a Holanda em relação a atuação de Ronaldinho: Acorda Ronaldinho (07/07/98).

A relação do técnico da França Aimé Jacquet, em 1998, com a imprensa de seu País, por exemplo, foi tumultuada e pode ser comparada a que Parreira tinha em 1994 com a imprensa brasileira, pois os dois deixaram os mundiais como campões. O treinador campeão, em 1998, após a final contra o Brasil afirmou no jornal Folha de São Paulo: Jamais perdoarei. Jamais (ao ser indagado se perdoaria a mídia de seu país, que o criticou com veemência na fase preparatória e na primeira fase da Copa (13/07/98). Outra declaração de Jacquet foi publicada no jornal $\mathrm{O}$ Globo: Aimé Jacquet, vitorioso, aproveita para mandar recado aos seus críticos: "Esta Copa não é deles" (13/07/98):

$\left.3^{\circ}\right)$ Tracos emocionais com 176 ocorrências $(17,4 \%)$ foi a terceira categoria mais identificada, ao enfatizar expressões emocionais protagonizadas por atletas, dirigentes, espectadores e pela própria imprensa. Quanto ao conteúdo, os dados mostraram que a categoria teve dois momentos, em função dos resultados das partidas: no primeiro, $\rho$ conteúdo esteve voltado à vitória e, no segundo à derrota. Ou seja, a imprensa veiculou todos os tipos de sentimentos presentes num espetáculo esportivo. Os protagonistas do Mundial, e também a imprensa, viveram momentos de alegria, de êxtase e de tristeza, de frustraçấ. A partir da cobertura realizada percebeu-se o quanto é difícil aos profissionais, que atuam nos veículos de comunicação, separarem emoção e razão, ou seja, fica claro que a imprensa toma posição e seus profissionais também torcem.

Na partida final, entre Brasil x França, foi onde a imprensa explorou mais a emoção (106 ocorrências contra 61 na semifinal), talvez por ser o jogo mais importante da competição, e aquele que poderia colocar a quinta estrela no uniforme da seleção. As maiores demonstrações de emocionalidade

\footnotetext{
${ }^{10}$ Ver mais detalhes em Hatje, M. Carvalho, S. e Palma, L. em A linguagem utilizada por três jornais brasileiros para descrever a atuação da seleção brasileira na Copa do Mundo de 1994. IN: Revista Comunicação. Movimento e Midia na Educação Física. Santa Maria: UFSM, 1998 , V.4, p. $19-30$
}

Revista Kinesis, Santa Maria, $N^{o}$ Especial, p. 76-154, nov. 2001 
aconteceram através da imagem de fotografia, onde imperou a tristeza do brasileiro, de norte a sul do país, após a derrota para a França
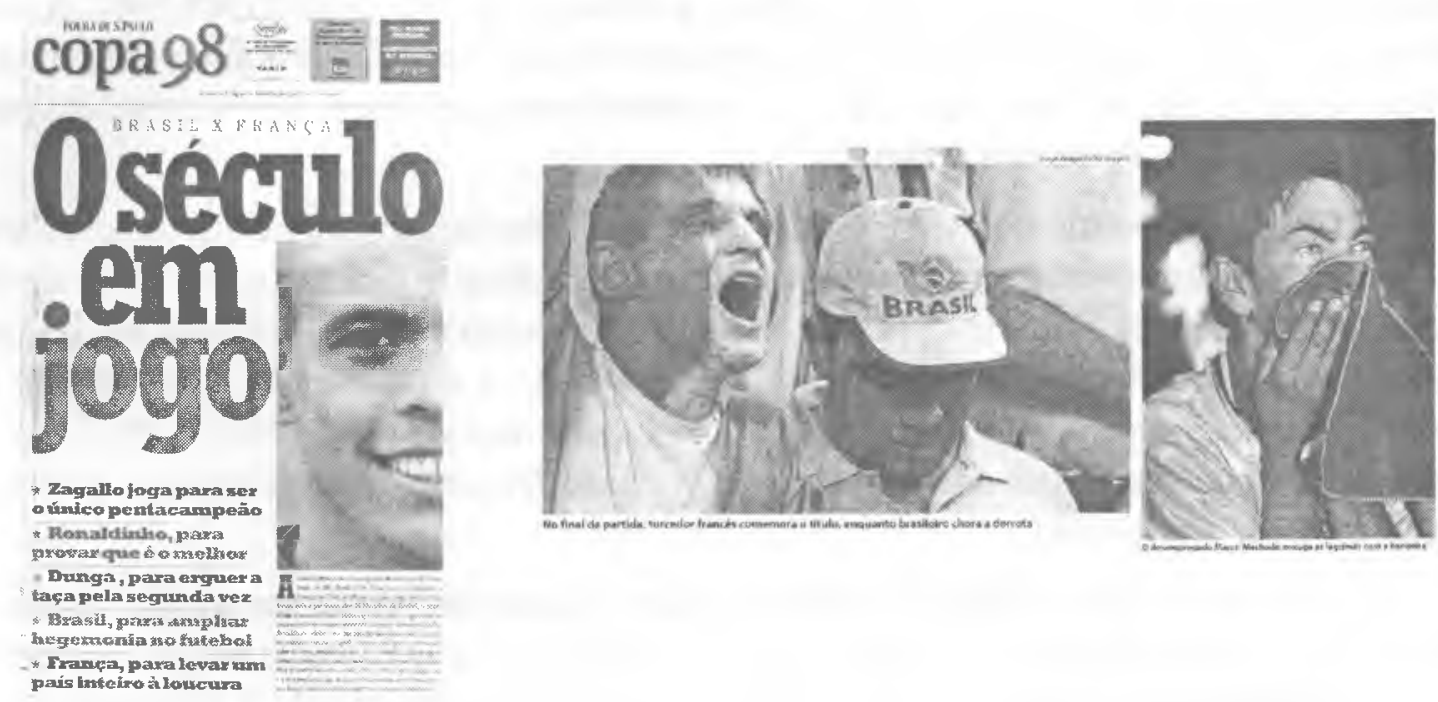

Figuras 5, 6 e 7 - A importância dada pela imprensa ao jogo ( $O$ século em jogo) e as expressões emocionais protagonizadas por torcedores, após a final entre Brasil x França em 12/07/98 (FSP, 13/ $07 / 98$, p. 10 e 11 )

A imprensa a todo momento se manifesta emocionalmente, através de seus profissionais. Zero Hora publicou um exemplo elucidativo: Vai que é nossa, Brasil (12/07/98). O Globo após o jogo contra a Holanda veiculou na capa do Caderno de esportes: Vai que é nossa, Taffarel (08/ 07/98).

$4^{\circ}$ ) Aspectos adjacentes às partidas. com 127 ocorrências $(13,2 \%)$, foi a quarta categoria mais presente. Ao envolver aspectos políticos, econômicos e históricos, mostra e confirma a importância do futebol na sociedade e na própria imprensa. Nessa perspectiva, os veículos credenciam a Copa do Mundo, como um megaevento e ratificam que o futebol está se tornando um negócio cada vez mais rentável. Durante a Copa, os veículos buscaram integrar o momento atual vivido pela sociedade, relacionando-o aos momentos históricos, sociais, políticos e econômicos que envolvem o futebol.

A valorização da história do futebol, principalmente o desempenho do Brasil em Copas do Mundo, foi regra na imprensa brasileira. Nos exemplares analisados, pelo menos 78 vezes, os veículos reportaram-se à história do Brasil nas Copas do Munḑo, perfazendo um total de
$8,1 \%$ em relação aos 962 registros.

A tristeza que tomou conta dos brasileiros alicerçou-se no retrospecto histórico do Brasil em Copas do Mundo, mas também na expectativa criada pela imprensa depois que o Brasil passou à final. Além de exaltar, principalmente atletas em detrimento da seleção que poderiam fazer a diferença na partida, e a publicação de declarações, antes da partida final, de pessoas com retrospecto baseado na confiança e na credibilidade no meio futebol, porque já foram campeões em Copas do Mundo (como Carlos Alberto Parreira e Pelé, por exemplo), aumentou ainda mais a esperança dos brasileiros.

A XVI edição da Copa do Mundo de 1998, não fugiu a regra dos investimentos e do público que crescem a cada ano. O comitê organizador investiu cerca de US\$ 400 milhões de dólares e aproximadamente de 1,7 bilhão de pessoas assistiram à final, dia 12 de julho. 
A briga no Mundial de 1998 ficou por conta das empresas fabricantes de material esportivo e começou bem antes do início da competição ${ }^{11}$. As duas protagonistas foram a alemã Adidas, a grande vencedora da Copa, e a norte-americana Nike (13/07/98). A Adidas, além de patrocinar a campeã França, forneceu as bolas oficiais do mundial e o material esportivo dos árbitros. Além disso patrocinou mais outras quatro seleções. A Nike também patrocinou cinco seleções, entre elas o Brasil.12131415

As questões políticas envolvendo o futebol também ficaram claras nas edições analisadas, principalmente os dias que antecederam a partida final e um dia após a derrota para a França. Há diferenças evidentes na cobertura sobre o retorno da seleção brasileira, nos jornais analisados. Muitas vezes as divergências entre o veículo e a CBF estão explícitas. O jornal paulista veiculou que a $C B F$ recua e seleção deve ir à Brasília $(11 / 07 / 98)$ e $C B F$ recua e leva seleção a FHC; Ao contrário do que pretendia, Ricardo Teixeira, da CBF, desistiu de desafiar o presidente FHC (11/07/98).

$\mathrm{O}$ jornal $\mathrm{O}$ Globo volta sua cobertura mais à figura do presidente da República e não tanto a CBF. A volta da seleção ao Brasil foi noticiada da seguinte forma: $F H$ vai receber jogadores no Planalto na terça-feira (11/07/98). Um dia após o jogo final, O Globo destaca: FH pede que a torcida receba bem a equipe (13/07/98). A Folha de São Paulo veiculou a seguinte fala do presidente FHC: Faltou sorte. Peço a todos que recebam a seleção com carinho. Continuamos os melhores do século (13/07/98).

A cobertura quando do retorno da seleção brasileira no jornal Zero Hora é basicamente informativa, de caráter mais objetivo do que os outros dois veículos. São raras as referências ao presidente da República e a CBF: Seleção retorna amanhã (13/07/98) e O avião desembarca em Brasília às $6 h$ (13/07/98) foram exemplos publicados.

$5^{\circ}$ ) Traços de violência, com 105 ocorrências $(10,8 \%)$, foi a categoria que apareceu em quinto lugar, embora fosse aquela com o maior número de subcategorias (49), das sete consideras à pesquisa. De forma geral, a imprensa não evidencia demasiadamente, aspectos de violência, mas o que chama a atenção é que das seis subcategorias mais veiculadas, três envolvem os meios de comunicação e a que mais ocorreu foi a Violência entre Meios de Comunicação (MC) e jogadores, com destaque ao lateral Zé Carlos ${ }^{16}$. A relação de antipatia, entre os MC e o lateral da seleção ficou evidente, especialmente quando ele substituiu Cafu, contra a Holanda. Das 31 ocorrências registradas como Violência entre MC e jogadores nos três veículos, 25 dizem respeito ao lateral Zé Carlos. Para exemplificar a aversão que a imprensa

\footnotetext{
${ }^{11}$ Para saber mais sobre a importância do marketing no futebol durante a Copa do Mundo de 1998 fłm como as empresas que patrocinaram todas as seleçôes ver jornal Folha de São Paulo, 2 de junho de 1998).

${ }^{12}$ A Nike possui um contrato de exclusividade com a CBF por dez anos, tornando-se patrocinadora da seleção brasileira por uma cifra estimada em 220 bilhões de dólares. Através deste contrato ela terá o direito de usar a imagem da seleção brasileira. Para leitura complementar sugere-se Brunoro \& Afif, 1997.

1: O mercado esportivo, considerando-se as diversas modalidades, movimentou algo em torno de 20 bilhões de dólares em todo mundo. A Nike, por exemplo, que patrocina a seleção brasileira de futebol, faturou aproximadamente 6,5 bilhões de dólares em 1996 por meio de vendas em todo mundo, sendo líder das marcas de material esportivo, desde 1997. (Santos, 1998).

${ }^{14} \mathrm{O}$ mercado esportivo brasileiro, o quinto do mundo, tem um faturamento de 6 bilhões de dólares por ano, somando-se todos os negócios, como ingressos, patrocínio, comércio de materiais esportivos, cotas de televisão, compra e venda de jogadores. O primeiro lugar é ocupado pelos Estados Unidos com um faturamento de 87 bilhões de dólares ao ano. O basquete, sozinho, responde por 5 bilhôes. (Brunoro \& Afiff, 1997).

${ }^{13}$ A Nike pretende transformar o brasileiro no herdeiro de Michel Jordan, astro da NBA. Ronaldinho possui contrato vitalício com a empresa e recebe 1 milhão de dólares por ano. (13/07/98)

${ }^{16}$ Os índices da subcategoria Violência entre Meios de Comunicação e Jogador, em todo trabalho, devem-se basicamente às críticas dirigidas pela imprensa ao jogador Zé Carlos. Pela ênfase dada, considerou-se as manifestações como uma forma de violência, pois em nosso entendimento foram veiculadas com o objetivo claro de desqualificar e destruir o jogador. As críticas, destrutivas, podem ser considerados como uma violência intrínseca.
}

Revista Kinesis, Santa Maria, $N^{o}$ Especial, p. 78-154, nov. 2001 
brasileira ostentou em relação a Zé Carlos pode-se destacar: Lateral tampão deixa defesa frágil (FSP-06/07/98); Zé Carlos treina mal, mas Zagallo não se preocupa (OG, 06/07/98); Lateral tem o menor salário (FSP, 07/07/98); o paulista Zé Carlos não teve uma atuação à altura do titular, Cafu, e transmitiu insegurança ao torcedor $(\mathrm{ZH}, 08 / 07 / 98)$ e $O$ imitador ganha uma missão séria (ZH- 06/07/98).

As subcategorias Violência entre Meios de Comunicação (MC) e jogadores, com 3,4\%, (33 ocorrências) e Linguagem bélica, com 2,6\% (25 ocorrências) foram as subcategorias mais exaltadas pela imprensa, nas partidas da semifinal e final; seguidas das subcategorias Violência entre MC e treinador 1,2\% (12 ocorrências); Violência entre MC e comissão técnica, com 0,9\% ( 9 ocorrências); Violência entre jogadores, com $0,8 \%$ ( 8 ocorrências) e Violência entre torcedores e jogadores, com $0,7 \%$ ( 7 ocorrências).

A utilização da linguagem bélica também foi explorada, no sentido de promover o espetáculo, através da rivalidade. Como exemplo pode-se destacar: A guerra está delarada (06/07/ 98 - FSP); Copa 98: a guerra está declarada (06/07/98-OG) e O inimigo é um perigo - Rivaldo, o matador da Dinamarca, desafia Bergkamp, o carrasco da Argentina (07/07/98, ZH), são exemplos.

$\left.6^{\circ}\right)$ Traços étnicos. com 98 ocorrências $(10,2 \%)$. Os conteúdos como o racismo e a xenofobia tiveram pouca incidência. Mas foi no jornal Folha de São Paulo, em que a subcategoria se evidenciou. A religiosidade (uso de símbolos como o camafeu e a cruz) e a superstição (Ritos, roupas e manias na torcida pelo penta - 12/07/98, OG), (Técnico diz que bola de cristal indica classificação - 06/07/98, FSP) dos brasileiros esteve presente na cobertura. A imprensa fez alusão a expressões religiosas e a fé para justificar ou projetar possíveis resultados (positivos). Embora o esporte moderno esteja vivenciando uma possível transição entre o sagrado e o profano, o sagrado e o místico ainda estão muito presentes no futebol e, são reforçados pela mídia.

Durante o período considerado na análise, os veículos exaltaram o futebol como um espetáculo que enfatiza a relação entre a secularização e a racionalização, características do esporte moderno e que estão imbuídas de questões como a religiosidade e a superstição que caracterizam, em parte, também o povo brasileiro. A todo momento, místico e sagrado se entrelaçam com o racional, o técnico e o científico.

A imprensa também evidenciou a questão da etnia e do nacionalismo do brasileiro, num total de $8,73 \%$ em relação a todas as unidades de registro (962). O racismo e a xenofobia também foram mencionados, chegando ao índice de 1,4\%. A ausência dą subcategoria Comparação étnica e nacionalista, na cobertura das duas partidas, é interessantę pois podemos perceber que a imprensa brasileira adota comportamento diferenciado na cobertura de um Mundial em relação a cobertura de campeonatos e eventos nacionais.

$7^{\circ}$ ) Traços sexistas. A imprensa brasileira, no período analisado, não evidenciou em textos e/ou fotos traços sexistas. Aspectos voltados a virilidade e sexualidade das pessoas envolvidas com o Mundial, sejam, torcedores, jogadores, treinadores ou dirigentes esportivos foram desprezados.

O índice geral de ocorrência das categorias na semifinal, nos jornais, evidencia, que:

Zero Hora exaltou as categorias Registros relativos à individualidades nas equipes nacional e adversária e Traços de Violência. com 23,3\% cada; 
Folha de São Paulo e O Globo destacaram a categoria Relações nacionais e internacionais. $35,2 \%$ e $31,3 \%$, respectivamente.

Em relação a subcategoria que somou o maior índice de ocorrência na partida da semifinal entre Brasil x Holanda, foi Exaltação de jogador da seleção nacional, com 43,4\%. Os responsáveis pelo índice são os jornais Zero Hora e O Globo. O iceberg Emerson brilhou $(\mathrm{ZH}$, 08/07/98) é exemplo elucidativo dessa constatação. Particularmente no jornal Zero Hora foi Exaltação de jogador da seleção nacional $(20.6 \%)$ : no jornal Folha de São Paulo Comentários e valores negativos ao adversário e às nacionalidades e Manifestação emocional de jogador da seleção nacional. com 13,1\% cada. A primeira subcategoria ratifica seu índice a partir de exemplos como Individualismo desafia Holanda (07/07/98) e a segunda Taffarel grita ao garantir classificação à final (08/07/98); e em O Globo Exaltação de jogador da seleção nacional (22.8\%).

$\mathrm{O}$ índice geral de ocorrência das categorias na final, nos jornais, mostra que:

Zero Hora enfatizou as categorias Registros relativos à individualidades nas equipes nacional e adversária e Tracos emocionais. com 28,6 \% cada;

A Folha de São Paulo e $\mathbf{O}$ Globo destacaram, a exemplo da semifinal, novamente as Relações nacionais e internacionais. com $27,7 \%$ e $24,9 \%$, respectivamente.

A subcategoria que somou o maior índice de ocorrência nos três jornais analisados na partida final foi Exaltação de jogador da selecão nacional. com 45,6\%. Os jornais Zero Hora e O Globo são novamente os responsáveis pelo índice. São exemplos dessa constatação: $O$ mágico contra o leão (ZH, 12/07/98); Rivaldo, estrela que sobe, é o termômetro da seleção (OG, 11/07/98).

Particularizando, a subcategoria que mais apareceu em Zero Hora foi Exaltação de jogador da seleção nacional (21\%); na Folha de São Paulo Comentários e valores negativos em relação a seleção nacional $(14 \%)$. Um exemplo que ilustra a constatação no jornal paulista é: Defesa é a pior desde a Copa de 38 (13/07/98); e em O Globo Exaltação de jogador da seleção nacional $(24,6 \%)$.

Quanto ao índice geral de ocorrência das categorias na semifinal e final, observando-se a hierarquização da informação (local de publicação) nos três veículos podemos concluir que:

$\mathrm{Na}$ capa contra/capa dos jornais analisados, as duas categorias que mais apareceram foram:

Relações nacionais e internacionais, com 38,2 \% das ocorrểncias. Exemplos que ilustram a categoria antes e depois da final: Corações aquecidos ( $\mathrm{ZH} \%$ 1/07/98) e França adia o sonto do penta (OG, 13/07/98).

Tracos emocionais com $21,8 \%$ das ocorrências.

As subcategorias que mais apareceram na capa e contracapa dos jornais, respectivamente, nas partidas da semifinal e final foram:

Zero Hora: Exaltação do patriotismo emocional $(22,2 \%)$ pode se exemplificado com: Um brado rutumbante (8/12/98) e Manifestações emocionais de torcedores $(50 \%)$.

Folha de São Paulo: Exaltação de jogador da seleção nacional $(55,6 \%)$ e Exaltação da etnia e do nacionalismo (30\%). Essa pode ser exemplificada com Brasil busca o penta na "final do século" (12/07/98). 
O Globo: Exaltação de jogador da seleção nacional $(22,2 \%)$ e Exaltação do patriotismo emocional da seleção nacional $(20 \%)$.

Na capa/contracapas dos cadernos de esporte veiculados nos jornais considerados à pesquisa, novamente se destacaram as categoria:

Relações nacionais e internacionais. com 32,4\% das ocorrências;

Traços emocionais com $23 \%$ das ocorrências. Um exemplo é Agüenta, coração! (OG, $7 / 12 / 98)$

As subcategorias que mais apareceram na capa e contracapa dos cadernos de esporte na semifinal e final foram

Zero Hora: Ridicularização do adversário (22,2\%): É hoje. Gomo por Gomo. (07/12/98) e Exaltação do patriotismo emocional da seleção nacional $(27.3 \%)$.

Folha de São Paulo: Caráter xenófobo-racista $(33,3 \%)$ e Exaltação de jogador da seleção nacional $(27,3 \%)$.

O Globo: Exaltação de jogador da seleção nacional (44.5\%) e Manifestações emocionais de torcedores $(45.4 \%)$.

Nas páginas internas, dos cadernos de esporte veiculados nos jornais analisados, as categoria mais destacadas foram:

Relações nacionais e internacionais. com $25,3 \%$ das ocorrências;

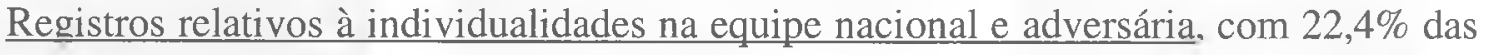
ocorrências.

As subcategorias que mais apareceram na páginas internas dos cadernos de esporte na semifinal e final foram

Zero Hora: Valorização da história do futebol (42.8\%). Exemplos que ratificam o índice foram publicados, principalmente, antes da partida final: E se o Brasil repetir 1950? (ZH, 12/07/98); A mitologia do futebol brasileiro foi consagrada com o título inédito de 58 e com o bi em 62 (FSP, 12/07/98). e Exaltação de jogador da seleção nacional $(34.4 \%)$.

Folha de São Paulo: Comentário e valores negativos do adversário e da nacionalidade $(21,4 \%)$ e Exaltação da etnia e do nacionalismo $(28.3 \%)$.

O Globo: Exaltação de jogador da seleção nacional (35.7\% Exaltação de jogador da seleção nacional $(37,3 \%)$.

\section{Conclusões}

A imprensa brasileira, durante a cobertura do Mundial de 1998, exaltou as características e os valores da seleção brasileira e das adversárias, saindo de suas peculiaridades estritamente futebolística e entrando em apelações emotivas e/ou símbolos da pátria. Também se evidenciou ridicularizações através de comentários negativos em relação a atuação ou à promoção' dos jogos entre Brasil x Holanda e Brasil x França. 
Diante disso, pode-se afirmar que a imprensa brasileira promove os espetáculos ao exaltar e criticar as equipes nacional e adversárias, criando, inclusive, a rivalidade entre os torcedores. Acrescenta-se que a imprensa estimula a ação competitiva, através da valorização de aspectos históricos das equipes e de valores que as caracterizam, com o uso de linguagem bélica. Outra forma de promover o jogo é exaltar atletas em detrimento do grupo, principalmente se este for disputado por seleções com tradição em Copas do Mundo e que possuam jogadores de destaque em nível mundial.

A promoção dos jogos também está diretamente relacionada à exaltação de valores/símbolos como a bandeira e as cores nacionais. Se torna ainda mais importante se for observada a passagem da seleção nacional de uma fase para outra na competição e a hierarquização das informações (local de publicação). Além de somar os maiores percentuais de ocorrência, foi a mais publicada nas capas dos jornais e nas capas dos cadernos de esporte, considerados locais nobres na imprensa - porque é nas capas onde são publicadas as informações consideradas mais importantes e/ou interessantes pelos editores - e com os quais o leitor tem o primeiro contato.
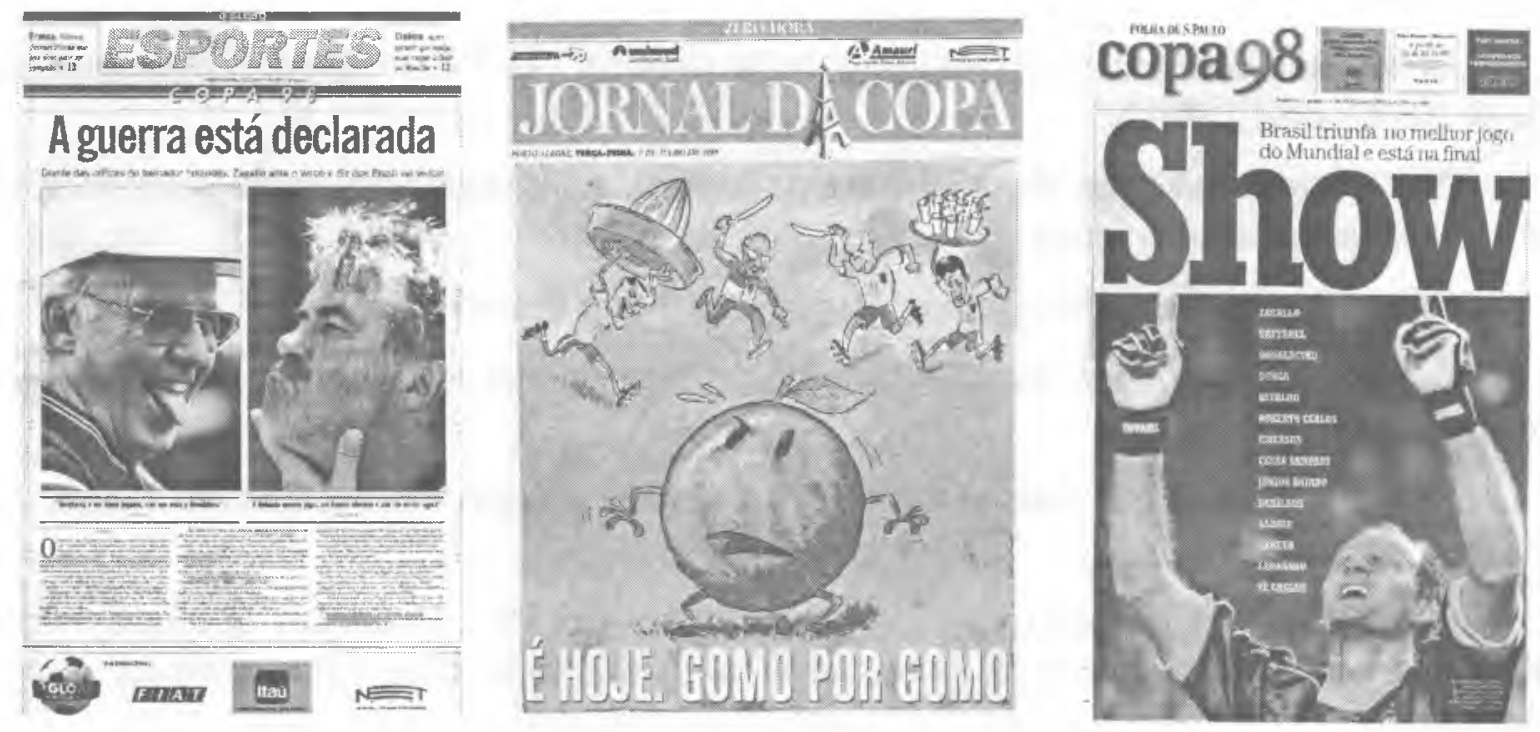

Figuras 8, 9 e 10 - Linguagem bélica, ridicularização/rivalidade e emoção: aspectos utilizados pela imprensa brasileira para a promoção do espetáculo esportivo (semifinal entre Brasil x Holanda - 07/07/98)

A imprensa brasileira durante a Copa do Mundo de 1998 foi muito mais informativa do que formativa, e suas publicações estiveram acompanhadas de grande carga emocional, característica inerente ao espetáculo esportivo. O resultado do uso constante de linguagem emotiva, contudo, não deve ser atribuído apenas a esse fator. Como a émoção é inerente ao ser humano, o jornalista esportivo, é antes de tudo também um torcedor. Ao produzir as informações a serem veiculadas, ele nem sempre consegue separar a emoção da razão. A imprensa promove e incentiva o espetáculo com emoção e, sobretudo, com o uso de linguagem bélica Essa foi, aliás, uma prática nos jornais brasileiros ao fazerem constantes referências aos sentimentos de tristeza e desespero que tomou conta dos brasileiros com a perda da Copa de 1950, no Brasil, e os sentimentos de euforia, êxtase e alegria na vitória de 1970, no México.

Nos três jornais analisados, o estilo de cobertura utilizado durante a Copa do Múndo pouco difere, embora Zero Hora e o Globo (de mesma linha editorial) e Folha de São Paulo apresentam diferenças nos coberturas dos fatos do dia-a-dia. De um modo geral pode-se dizer

Revista Kinesis, Santa Maria, $N^{\circ}$ Especial, p. 82-154, nov. 2001 
que todos apelam demasiadamente para a promoção do espetáculo esportivo, através da emoção, e não há qualquer preocupação em veicular avaliações de atletas e/ou equipes, feitas pelos próprios profissionais. Mesmo que tenha havido um esforço para veicular informações objetivas ou neutras, o jornal Folha de São Paulo foi o veículo que veiculou o maior número de informações no estilo informativo. Zero Hora e O Globo, foram mais subjetivos e, conseqüentemente, mais parciais.

Os veículos dedicaram praticamente todo o espaço das capas dos jornais ao futebol, especialmente nos dias dos jogos da semifinal e da final e ao dia subsequente a cada um deles. Em Zero Hora, por exemplo, raros foram os espaços a outros assuntos que não o futebol nas edições analisadas.

A rivalidade que normalmente se percebe na cobertura de campeonatos nacionais, em relação as equipes e atletas, não aconteceu na Copa do Mundo. O bairrismo que caracteriza, de certa forma a imprensa brasileira, não foi registrado nas 18 edições analisadas durante o Mundial. Tanto que o jornal Folha de São Paulo exaltou atletas gaúchos, o jornal Zero Hora enfatizou jogadores paulistas, o que dificilmente aconteceria no cotidiano. Uma das razões, talvez, seja o retrospecto favorável dos jogadores em Copas do Mundo, como é o caso de Taffarel e Dunga, entre os mais evidenciados.

Outro ponto a destacar é que a imprensa ao utilizar uma linguagem, com características emocionais e bélica/militar, trabalha ora para atender as exigências de mercado (ampliar a vendas dos jornais ou estimular o leitor a consumir a informação), ora para atender a questão envolvendo aspectos educativos/formativos. Para que ela cumpra sua função educativa, entre elas a de estimular a prática desportiva no sentido de buscar uma melhor qualidade de vida, a utilização constante do vocabulário bélico e a exaltação demasiada de atletas deverá ser reavaliada pelos profissionais que atuam na editoria de esporte. Direta ou indiretamente esses podem ser fatores que incitam a violência (principalmente os atos protagonizados por torcedores) e que desvirtuam a função do esporte e da própria atividade física.

\section{Referências bibliográficas}

ALCOBA LOPES, Antônio. El periodismo deportivo en la sociedad moderna. Madrid: Editorial Augusto E. Pila Teleña, 1980. 311p.

. Como hacer periodismo deportivo. Madrid: Editorial Paraninfo, s/d 201 p.

La prensa deportiva: tratamiento inédito sobre elsgénero específico del deporte y cómo hacer una publicación deportiva ideal. Madrid: Instituto Universitario Olímpico de Ciencias del Deporte-Universidad Complutense de Madrid, 1999. 207p.

BAHIA, Juarez. Jornal, história e técnica: as técnicas do jornalismo. São Paulo: Ática, 1990. BARDIN, L. Análise de conteúdo. São Paulo: Edições 70, 1977.

BELTRÃO, Luiz. A imprensa informativa. São Paulo: Livraria Editora Importadora Americana Ltda, 1969, coleção Mass-Media.

BRUNORO, José Carlos e AFIF, Antonio. Futebol 100\% profissional. São Paulo: Gente, 1997.

CAMARGO, Vera Regina Toledo. O telejornalismo e o esporte-espetáculo. São Bernardo do Campo: Tese de Doutoramento, 1998. 
CAPINASSÚ, José Maurício. A linguagem popular do futebol. São Paulo: Ibrasa, 1988.

Comunicação e transgressão no esporte. São Paulo: Ibrasa, 1997.

CARVALHO, S; HATJE, M. Comunicação, Movimento e Mídia na Educação Física. Santa Maria: UFSM, 1998.

Comunicação, Movimento e Mídia na Educação Física. Santa Maria: UFSM, 1999, v.2.

CONSTANTINO, José Manuel. O desporto e a comunicação social. IN: Revista Horizonte, v. VIII, nº 48. Lisboa, 1992.

DAMATTA, Roberto. Antropologia do óbvio: notas em torno do significado social do futebol brasileiro. In Dossiê Futebol, Revista USP. São Paulo, 1994, nº 22.

DAOLIO, Jocimar. Cultura: educação física e futebol. Campinas/SP: Unicamp, 1997.

DUARTE, Orlando. Todas as copas do mundo. São Paulo: Makron Books, 3. ed., 1994.

ELÍADE, M. O sagrado e o profano: a essência das religiões. São Paulo: Martins Fontes (1992).

Imagens e símbolos - ensaio sobre o simbolismo mágico - religioso. São Paulo: Martins Fontes.

ELIAS, N., DUNNING, E. A busca da exitação. Lisboa: DIFEL, 1992.

ERBOLATO. Mário. Jornalismo especializado: emissão de textos no jornalismo impresso. São Paulo: Atlas, 1981.

Técnicas de codificação em jornalismo: redação, captação e edição do jornal diário. Petrópolis: Vozes, 1985.

FLEURY, Suzy. Competência emocional: o caminho da vitória para equipes de futebol. São Paulo: Gente, 1998.

GONZÁLEZ, José Mosquera; SAAVEDRA, Miguel. El análisis de contenido aplicado a las notícias deportivas que aparecen en la prensa escrita. Una propuesta metodológica para el estudio de las informaciones sobre el R.C. Deportivo de La Coruña. Galícia/ Espanha: INEFC, 1996.

HATJE, Marli. Jornalismo especializado: a segmentação em busca da seletividade - uma proposta. IN Revista Signo, v.19, n 27. Santa Cruz do Sul: Unisc, 1994.

O jornalismo esportivo impresso do Rio Grande do Sul de 1945 a 1995: a história contada por alguns de seus protagonistas. Santa Maria: UFSM-CEFD/Dissertação de Mestrado, 1996.

A cobertura da Copa do Mundo pela imprensa brasileira. IN: Kiovale Jornal. Santa Cruz do Sul, 10 de abril de 1999.

HATJE, M.; CARVALHO, S. PALMA, L. A linguagem utilizada por três jornais para descrever a atuação da seleção brasileira de futebol na Copa do Mundo de 1994. IN: CARVALHO, S. e HATJE, M. Comunicação, Movimento e Mídia na Educação Física. Santa Maria: UFSM, v. 4, 1998

—_ A atuação da seleção brasileira de futebol nas Copas do Mundo de 94 e 98 através da linguagem impressa. IN: XI Congresso Brasileiro de Ciências do Esporte. Florianópolis, 1999.

HELAL, R. Passes e impasses: futebol e cultura de massa no Brasil. Petrópolis/RJ: Vozes, 1997.

LEVER, J. A loucura do futebol. São Paulo: Record, 1983.

MANUAL DE REDAÇÃO E ESTILO - O GLOBO. São Paulo: O Globo, 1992.

Revista Kinesis, Santa Maria, $N^{o}$ Especial, p. 84-154, nov. 2001 
MANUAL DE ÉTICA, REDAÇÃO E ESTILO - ZERO HORA. Porto Alegre: L\&PM, 1994. MARQUES DE MELO, José. Jornalismo comparado. São Paulo: Pioneira (1972).

—. Para uma leitura crítica da comunicação. São Paulo: Summus, 1985.

A opinião no jornalismo brasileiro. São Paulo: Vozes, 1994.

NOVO MANUAL DA REDAÇÃO - FOLHA DE SÃO PAULO. São Paulo: Folha de São Paulo, 1992.

ORLANDI, E. A linguagem e seu funcionamento: as formas do discurso. São Paulo: Brasiliense, 1983.

ORTIZ, Renato. A moderna tradição brasileira. Cultura brasileira e indústria cultural. São Paulo: Brasiliense, 1991.

PALLARÉS, Carlos Marco. Identidad étnica, nacionalismo, emociones y violência en el fútbol. Lleida/Espanha: INFEC, Universitat de Lleida, 1997.

REIS, Heloisa H.B dos. Futebol e Sociedade: as manifestações da torcida. Campinas/SP: Tese de doutorado, 1998.

REVISTA PLACAR. 100 anos de futebolo no Brasil - de Charles Miller ao tetra mundial. Outubro, $1994, \mathrm{n}^{\circ} 1097$.

RODRIGUES, Aroldo. Psicologia social. Rio de Janeiro: Vozes, 1988.

RODRIGUES, Nelson. A Pátria em Chuteiras: novas crônicas de futebol. (Ruy Castro, org).

São Paulo: Companhia das Letras, 1994.

SANTOS, José Luiz dos. O que é cultura. São Paulo: Brasiliense, 1994 (Coleção primeiros passos).

SANTOS, Tarcyanie Cajueiro. Dos espetáculos de massa às torcidas organizadas: paixão, rito e magia no futebol. São Paulo: ECA (dissertação de mestrado), 1998.

TUBINO, Manuel Gomes. Dimensões sociais do esporte. São Paulo: Cortez. 1992.

Jornais

Folha de São Paulo, dias 6,7, 8, 11, 12 e 13 de julho de 1998.

O Globo, dias 6,7,8,11,12 e 13 de julho de 1998.

Zero Hora, dias 6, 7, 8, 11, 12 e 13 de julho de 1998.

\title{
The major press: values and features tramsmitted by brazilian newspapers to describe the participation of the brazilian football team in the World Cup of 1998 in France
}

\begin{abstract}
This paper had for objective to analyse the values and or features transmitted through he content used by Brazilian newspapers to describe the participation of the Brazilian football team and its opponents in both the semi-final and
\end{abstract}


the final game in the World cup of 1998 in France. The content analysis approach was applied to the covering accomplished by the newspapers Folha de São Paulo (São Paulo), O Globo (Rio de Janeiro), and Zero Hora (Porto Alegre) on the 6th, 7th, 8th, 11th, 12th, and 13th July, 1998, during the period of both the semi-final (Brazil $\mathrm{x}$ Holland) and the final (Brazil $x$ France). Seven categories of analysis were defined which in turn were divided into subcategories. In the total 962 units of analysis of the informative genre were taken into account (headlines, subheads, leads, and photographs/captions). The discussion of the data was centred on the quantitative and qualitative aspect and a comparative analysis among the newspapers was carried out. The analysed Brazilian press transmits and highlights values and features inherent to football and to the Brazilian people themselves during the World cup time. It also highly praises single athletes in detriment of the group, and explores, promotes, and stimulates the sporting shows through the use of emotional language/images, warlike and military expressions to stimulate the rivalry. In general the content of the newspapers was characterized as being more informative than educational and or formative.

Keywords: sporting journalism; communication and sport; physical education and media. 